PREPARED FOR THE U.S. DEPARTMENT OF ENERGY, UNDER CONTRACT DE-AC02-76CH03073

PPPL-3707

PPPL-3707

UC-70

Gyrokinetic Calculations of Microinstabilities and Transport During RF H-Modes on Alcator C-Mod

by

M.H. Redi, C. Fiore, P. Bonoli, C. Bourdelle, R. Budny, W.D. Dorland, D. Ernst, G. Hammett, D. Mikklesen, J. Rice, and S. Wukitch

June 2002
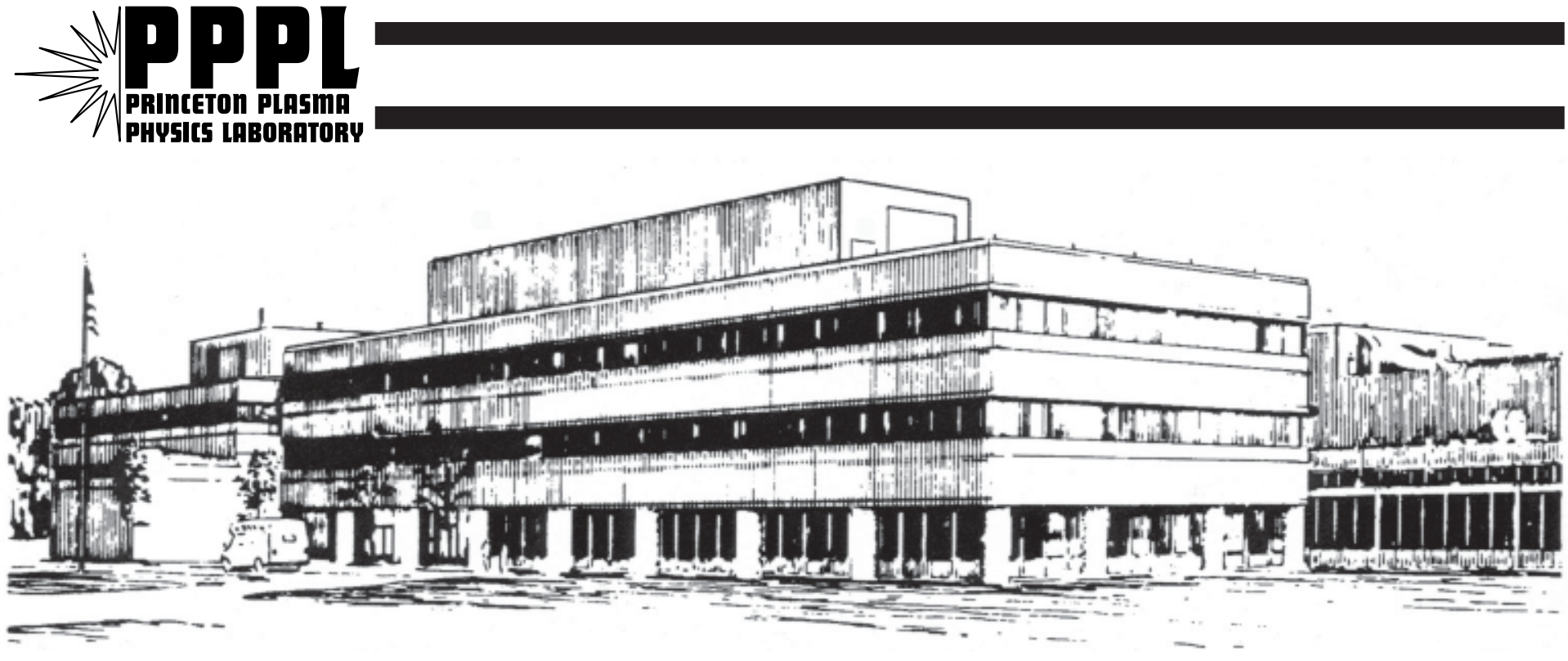

PRINCETON PLASMA PHYSICS LABORATORY PRINCETON UNIVERSITY, PRINCETON, NEW JERSEY 


\section{PPPL Reports Disclaimer}

This report was prepared as an account of work sponsored by an agency of the United States Government. Neither the United States Government nor any agency thereof, nor any of their employees, makes any warranty, express or implied, or assumes any legal liability or responsibility for the accuracy, completeness, or usefulness of any information, apparatus, product, or process disclosed, or represents that its use would not infringe privately owned rights. Reference herein to any specific commercial product, process, or service by trade name, trademark, manufacturer, or otherwise, does not necessarily constitute or imply its endorsement, recommendation, or favoring by the United States Government or any agency thereof. The views and opinions of authors expressed herein do not necessarily state or reflect those of the United States Government or any agency thereof.

\section{Availability}

This report is posted on the U.S. Department of Energy's Princeton Plasma Physics Laboratory Publications and Reports web site in Fiscal Year 2002. The home page for PPPL Reports and Publications is: http://www.pppl.gov/pub_report/

DOE and DOE Contractors can obtain copies of this report from:

U.S. Department of Energy

Office of Scientific and Technical Information

DOE Technical Information Services (DTIS)

P.O. Box 62

Oak Ridge, TN 37831

Telephone: (865) 576-8401

Fax: (865) 576-5728

Email: reports@adonis.osti.gov

This report is available to the general public from:

National Technical Information Service

U.S. Department of Commerce

5285 Port Royal Road

Springfield, VA 22161

Telephone: 1-800-553-6847 or

(703) 605-6000

Fax: (703) 321-8547

Internet: http://www.ntis.gov/ordering.htm 


\title{
GYROKINETIC CALCULATIONS OF MICROINSTABILITIES AND TRANSPORT DURING RF H-MODES ON ALCATOR C-MOD
}

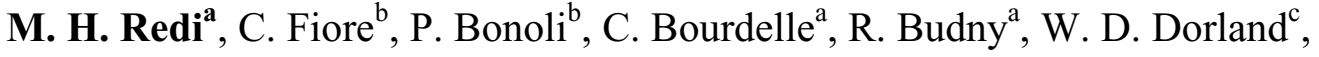

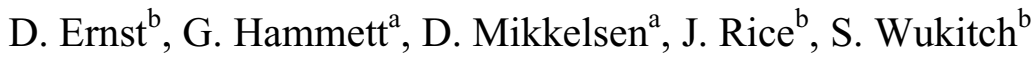 \\ ${ }^{a}$ Princeton Plasma Physics Laboratory, Princeton, NJ 08540, USA \\ ${ }^{b}$ Plasma Science and Fusion Center, MIT, Cambridge, MA 02139, USA

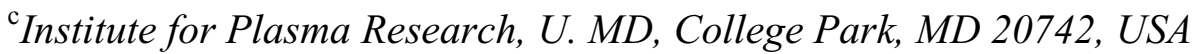

\section{Introduction}

Physics understanding for the experimental improvement of particle and energy confinement is being advanced through massively parallel calculations of microturbulence for simulated plasma conditions. The ultimate goal, an experimentally validated, global, nonlocal, fully nonlinear calculation of plasma microturbulence is still not within reach, but extraordinary progress has been achieved in understanding microturbulence, driving forces and the plasma response in recent years.

In this paper we discuss gyrokinetic simulations of plasma turbulence ${ }^{1,2}$ being carried out to examine a reproducible, H-mode, RF heated experiment on the Alcator CMOD tokamak ${ }^{3}$, which exhibits an internal transport barrier (ITB) ${ }^{4,5,6,7}$. This off axis RF case represents the early phase of a very interesting dual frequency RF experiment, which shows density control with central RF heating later in the discharge. The ITB exhibits steep, spontaneous density peaking: a reduction in particle transport occurring without a central particle source. Since the central temperature is maintained while the central density is increasing, this also suggests a thermal transport barrier exists. TRANSP analysis shows that $\chi_{\text {eff }}$ drops inside the ITB $^{6}$. Sawtooth heat pulse analysis also shows a localized thermal transport barrier ${ }^{7}$. For this ICRF EDA H-mode, the minority resonance is at $r / a \geq 0.5$ on the high field side. There is a normal shear profile, with q monotonic.

TRANSP analysis is used to set initial conditions, with $\quad T_{i}$ not assumed equal to measured $T_{e}$, but rather $T_{i}$ is found from HIREX spectroscopic and neutron data on Alcator C-MOD.and is consistent with $\chi_{i} \sim \chi^{\text {Chang-Hinton }}$. The simulations, which solve the gyrokinetic Vlasov-Maxwell system, are run out for 10,000 time steps, until the microinstability growth rates, $\gamma$, and real frequencies, $\omega$, are verified to have converged and the usual measure of 
the electrostatic potential, $\ln |\phi|^{2}$, is verified to be linearly increasing, in cases that are designated unstable. $\mathbf{E} \times \mathbf{B}$ shearing rates have been estimated from measurements of toroidal rotation but are not of concern here because at the time of interest, the toroidal rotation is near zero, changing from strong co to counter rotation as the ITB is established.

\section{Simulations with the GS2 Gyrokinetic Microstability Code}

Linear, fully electromagnetic, gyrokinetic, flux tube calculations of microturbulence for four species (hydrogen, deuterium, boron and electrons) are being used to examine the early stage of formation of the ITB, before a steep electron density gradient is established (Fig. 1). At this point in time, microturbulent instability for three plasma radii is simulated, yielding predicted behavior inside, at and outside the ITB, at radii located at $\mathrm{r} / \mathrm{a}=0.25,0.45$, 0.65 for zones 5, 9 and 13 of 20 equally spaced radial zones. The sensitivity of the microturbulent stability has been examined through the sensitivity of the calculated real frequencies and growth rates to particular driving forces across the plasma (Fig. 2)

The simulations were carried out on the NERSC T3E supercomputer, using 40-64 parallel processors. We obtain microturbulent growth rates for values of $k_{\perp} \rho_{i}$ from 0.1 to 80 including the influences of ITG, TEM and ETG modes (Figs. 3 and 4). The stability analysis shows that just inside the barrier $(r / a \sim 0.45)$ no mode is strongly growing for $0.2<k_{\perp} \rho_{i}<0.8$. Outside the ITB a clear signature is found for the toroidal ion temperature gradient mode. In the plasma core, modes with $\omega<0$ are unstable at $k_{\perp} \rho_{i} \leq 0.4$; there are no strongly growing modes at $0.5 \leq k_{\perp} \rho_{i} \leq 0.8$. The apparently unstable mode at $k_{\perp} \rho_{i}=0.1$ is not converged and does not have a well defined eigenfunction. At higher values of $k_{\perp} \rho_{i}$, the TEM (usually found near $k_{\lrcorner} \rho_{i} \sim 1$ ) is not unstable, while the ETG (peaked at $k_{\perp} \rho_{i} \sim 25$ ) is strongly unstable at, and outside the barrier, and stable in the core (Fig. 3,4). Anomalous $\chi_{i}$ is associated with ITG so that we expect reduced ion thermal confinement at, and within the ITB. Anomalous $\chi_{e}$ is associated with strong ETG, and the mixing length model would predict $1 / 2$ for the ratio of $\chi_{e}$ at the ITB to that outside. Sawtooth heat pulse propagation measurements of similar experiments have shown that the effective $\chi^{\text {heatpulse }}$ is reduced (by factor $\sim 10$ ) in a narrow radial region of $\sim 1 \mathrm{~cm}$, located near the foot of the particle barrier, but not necessarily within the barrier ${ }^{7}$. Reduced microinstability growth rates predicted at the barrier are consistent with the observed reduced transport.

\section{Sensitivity Studies}


Figure 2 shows the radial variaton of drift mode driving and stabilizing parameters for the experiment at the time of interest. It is found that either decreasing the plasma electron density gradient or increasing the plasma electron temperature gradient causes the ITG mode to be destabilized in the transport barrier region. The growth rates are more strongly elevated (factor 25 ) by doubling $\left(\nabla \mathrm{T}_{\mathrm{e}}\right) / \mathrm{T}_{\mathrm{e}}$ than by reducing $\left(\nabla \mathrm{n}_{\mathrm{i}}\right) / \mathrm{n}_{\mathrm{i}}$ by 2 . We also find that $\eta_{i}$ increases as $r / a$ increases, as does the normalized electron temperature gradient. These and the increasing inverse gradient for the primary impurity, boron (4\%), may be stabilizing the ITG in the core. The role of magnetic shear, increasing with $r / a$, is still to be examined.

\section{Conclusions}

Just before ITB formation, conditions have been established for which a peaked density profile can occur and will persist. Ware pinch provides sufficient fueling to account for a sustained ITB peaked density profile ${ }^{7}$. Microturbulent driving forces are not strong enough to provide anomalous transport through the barrier, since there are no strong instabilities at the ITB. Outside the barrier, ITG and ETG modes are linearly unstable. The sensitivity studies suggest that the observation of ITB with off-axis but not on-axis RF, is due to weaker $\left(\nabla \mathrm{T}_{\mathrm{e}}\right) / \mathrm{T}_{\mathrm{e}}$ at the barrier. However, ITB also occurs spontaneously in the CMOD ohmic H-mode ${ }^{4}$. The full story will require a detailed examination and comparison of the many driving and damping forces operating in both of these intriguing experiments.

\section{Acknowledgement}

We are glad to acknowledge the experimental and diagnostic teams at Alcator CMOD which provided the data and basis for the analysis in this paper. Research supported by U. S. DOE Contract DE-AC02-76CH03073.

1. M. Kotschenreuther, et al., Comp. Phys. Comm. 88, 128 (1995).

2. W. Dorland, et. al., Phys. Rev. Lett. 85, 5579 (2000).

3. I. H. Hutchinson et al., Phys. Plas. 1, 1511 (1994).

4. C. L. Fiore, et al. Phys. Plas. 8, 2023 (2001).

5. J. Rice, et al., Nuclear Fusion, in press (2002).

6. P. Bonoli, et. al, $18^{\text {th }}$ IAEA, Sorrento, Italy, IAEA-CN-77, EXP4/01 (Oct.,2000.)

7. S. Wukitch, et al., Phys. Plas. 9, 2149 (2002). 


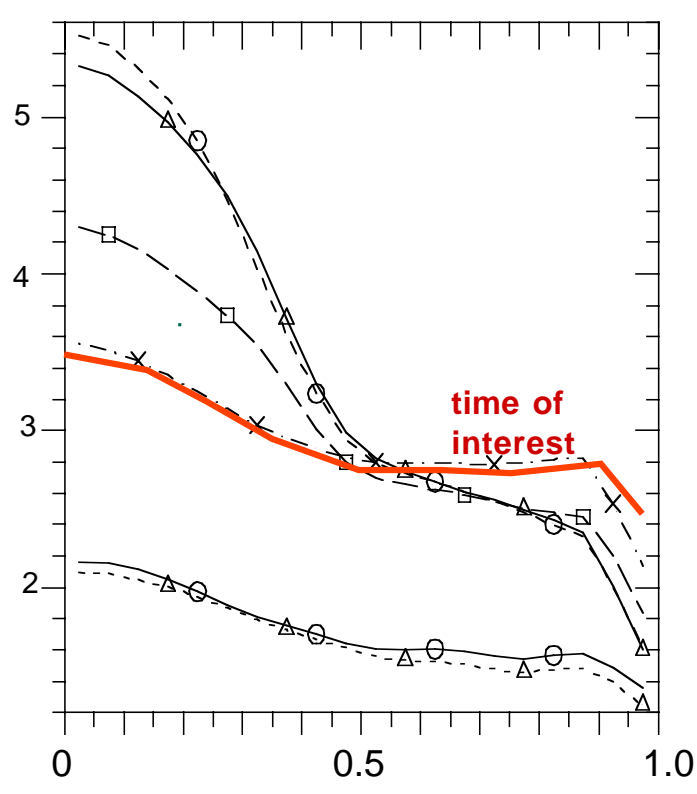

Fig. 1 Electron density $\left(10^{14} / \mathrm{cm}^{3}\right)$ versus radius ( $r / a)$, showing evolution from ohmic phase to RF Hmode ITB density peaked phase. Timeslices every $0.2 \mathrm{sec}$, from 0.5 to $1.4 \mathrm{sec}$.

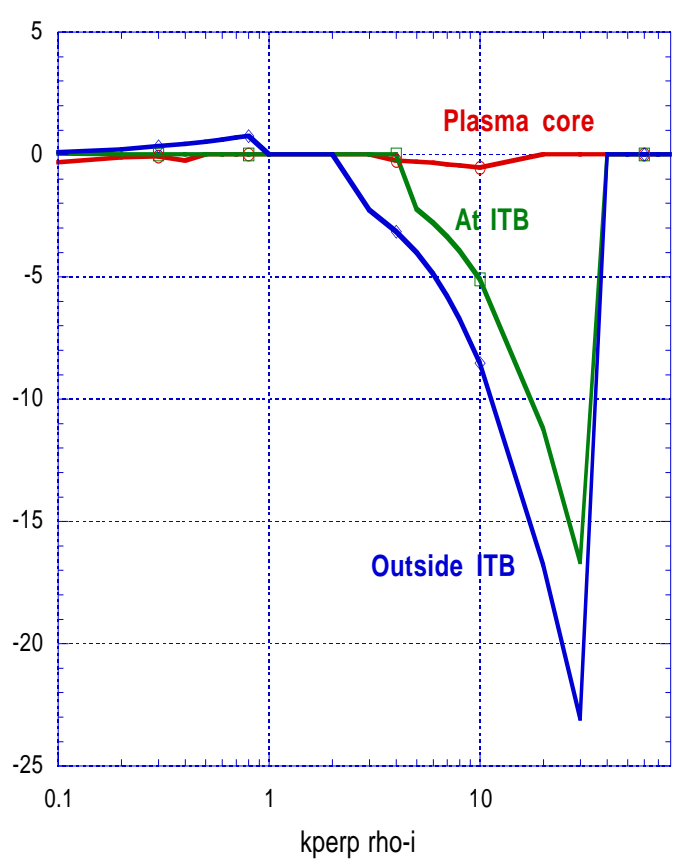

Fig. 3 Real frequencies ( 106/sec) of drift mode microturbulence inside, at and outside the ITB

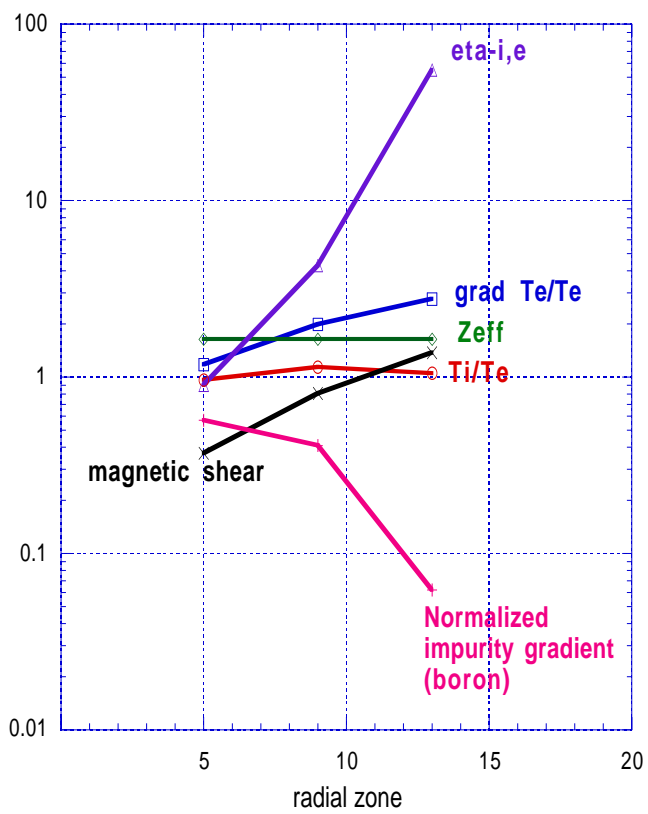

Fig. 2 Normalized driving forces for drift mode microturbulence are balanced to stabilize instabilities inside and at the ITB, compared to outside the ITB

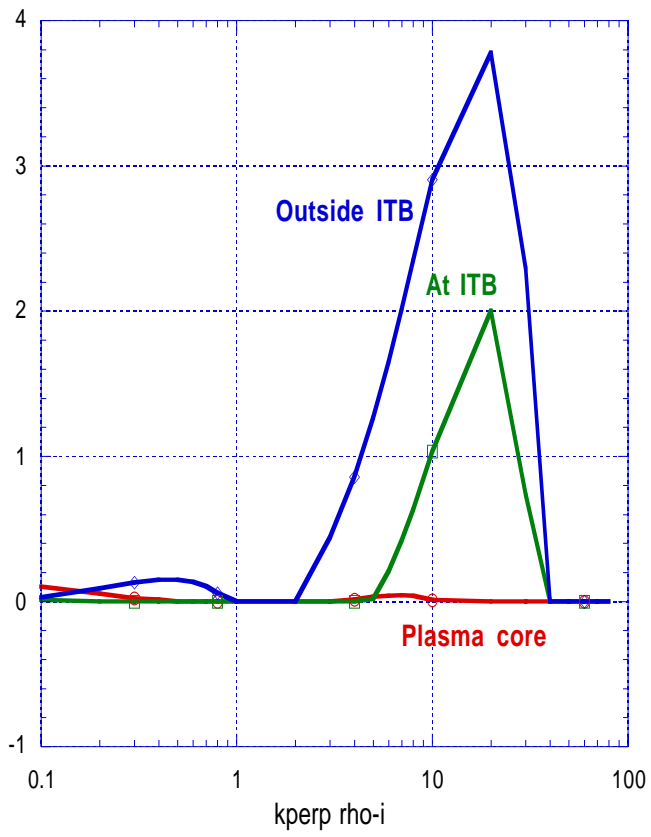

Fig. 4 Real growth rates ( 106/sec) inside, at and outside the ITB 


\section{External Distribution}

Plasma Research Laboratory, Australian National University, Australia

Professor I.R. J ones, Flinders University, Australia

Professor J oão Canalle, Instituto de Fisica DEQ/IF - UERJ , Brazil

Mr. Gerson O. Ludwig, Instituto Nacional de Pesquisas, Brazil

Dr. P.H. Sakanaka, Instituto Fisica, Brazil

The Librarian, Culham Laboratory, England

Library, R61, Rutherford Appleton Laboratory, England

Mrs. S.A. Hutchinson, JET Library, England

Professor M.N. Bussac, Ecole Polytechnique, France

Librarian, Max-Planck-Institut für Plasmaphysik, Germany

J olan Moldvai, Reports Library, MTA KFKI-ATKI, Hungary

Dr. P. Kaw, Institute for Plasma Research, India

Ms. P.J . Pathak, Librarian, Insitute for Plasma Research, India

Ms. Clelia De Palo, Associazione EURATOM-ENEA, I taly

Dr. G. Grosso, Instituto di Fisica del Plasma, Italy

Librarian, Naka Fusion Research Establishment, J AERI, J apan

Library, Plasma Physics Laboratory, Kyoto University, J apan

Research Information Center, National Institute for Fusion Science, J apan

Dr. O. Mitarai, Kyushu Tokai University, J apan

Library, Academia Sinica, Institute of Plasma Physics, People's Republic of China

Shih-Tung Tsai, Institute of Physics, Chinese Academy of Sciences, People's Republic of China

Dr. S. Mirnov, TRINITI, Troitsk, Russian Federation, Russia

Dr. V.S. Strelkov, Kurchatov Institute, Russian Federation, Russia

Professor Peter Lukac, Katedra Fyziky Plazmy MFF UK, Mlynska dolina F-2, Komenskeho Univerzita, SK-842 15 Bratislava, Slovakia

Dr. G.S. Lee, Korea Basic Science Institute, South Korea

Mr. Dennis Bruggink, Fusion Library, University of Wisconsin, USA

Institute for Plasma Research, University of Maryland, USA

Librarian, Fusion Energy Division, Oak Ridge National Laboratory, USA

Librarian, Institute of Fusion Studies, University of Texas, USA

Librarian, Magnetic Fusion Program, Lawrence Livermore National Laboratory, USA

Library, General Atomics, USA

Plasma Physics Group, Fusion Energy Research Program, University of California at San Diego, USA

Plasma Physics Library, Columbia University, USA

Alkesh Punjabi, Center for Fusion Research and Training, Hampton University, USA

Dr. W.M. Stacey, Fusion Research Center, Georgia Institute of Technology, USA

Dr. J ohn Willis, U.S. Department of Energy, Office of Fusion Energy Sciences, USA

Mr. Paul H. Wright, Indianapolis, Indiana, USA 
The Princeton Plasma Physics Laboratory is operated by Princeton University under contract with the U.S. Department of Energy.

\author{
Information Services \\ Princeton Plasma Physics Laboratory \\ P.O. Box 451 \\ Princeton, NJ 08543
}

Phone: 609-243-2750

Fax: 609-243-2751

e-mail: pppl_info@pppl.gov

Internet Address: http://www.pppl.gov 